\title{
Reseña del libro coordinado por Daniela Rawicz, Leer a Simón Rodríguez. Proyecto para América'
}

Gabriela Bayona-Trejo
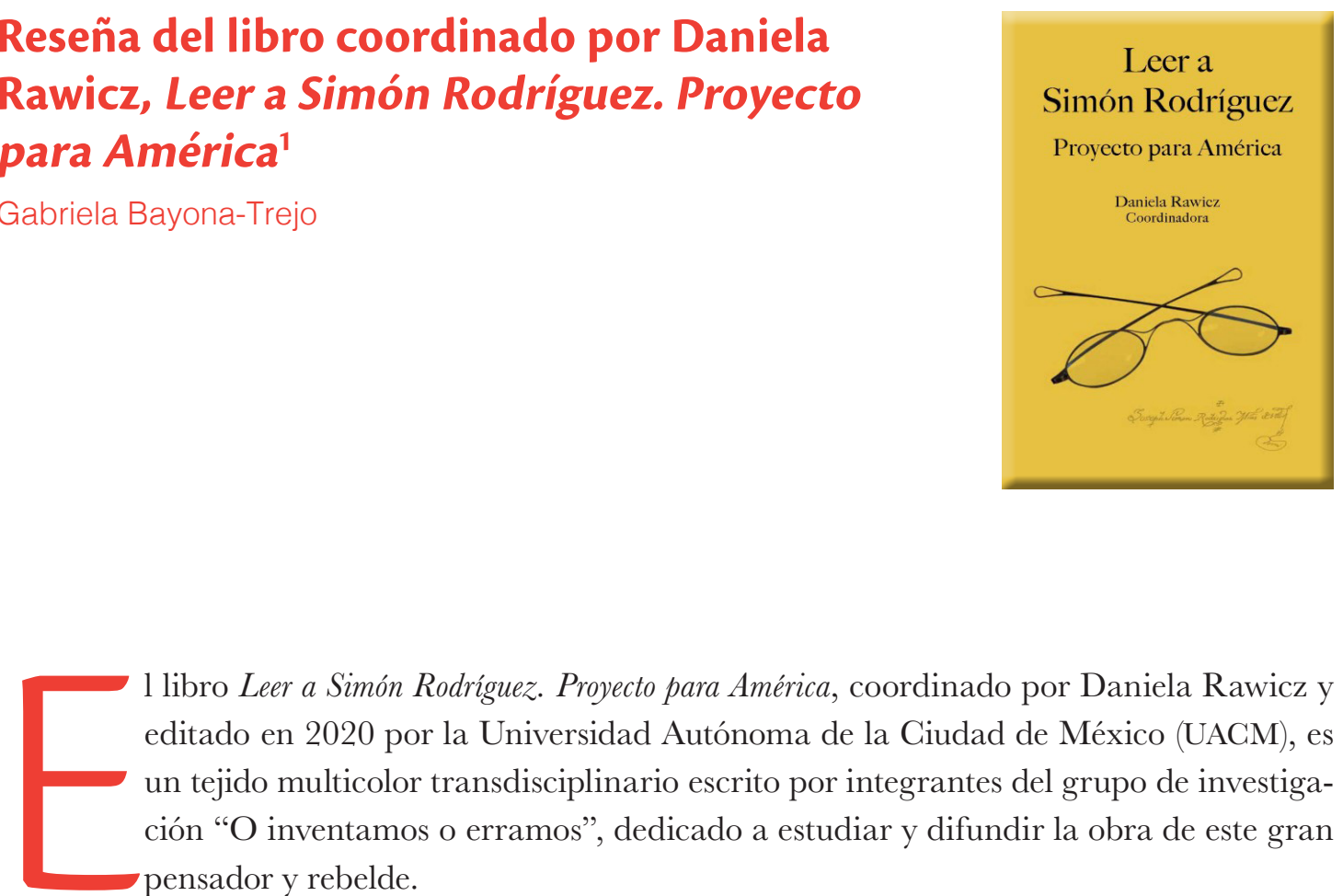

1 libro Leer a Simón Rodríguez. Proyecto para América, coordinado por Daniela Rawicz y editado en 2020 por la Universidad Autónoma de la Ciudad de México (UACM), es un tejido multicolor transdisciplinario escrito por integrantes del grupo de investigación "O inventamos o erramos", dedicado a estudiar y difundir la obra de este gran pensador y rebelde.

Los diez ensayos que componen el libro iluminan desde distintos ángulos los anhelos y propuestas pedagógicas, políticas, filosóficas y expresivas de quien poco a poco ha dejado de ser meramente recordado por haber sido maestro de otro Simón, Simón Bolívar, el gran libertador, para volverse una figura fundamental para entender la identidad, el pasado y el futuro de nuestras sociedades americanas.

Simón Rodríguez es la fuente de inspiración y el punto de encuentro de cada ensayo, aunque, como ya mencioné, se trata de distintos enfoques de estudio. Desde el título, este libro es una invitación a acercarse a leer la obra de Rodríguez, pero... ¿Quién fue Simón Rodríguez y por qué hay que leerlo? El subtítulo es la respuesta que nos da esta obra: "Proyecto para América". Entre las páginas de estos diez ensayos podemos vislumbrar que Rodríguez fue un hombre adelantado a su época, pues sus ideas nos remiten a este sueño libertario de unión entre nuestros pueblos que lo hermana con tantos otros pensadores y políticos latinoamericanos como Paulo Freire, Eduardo Galeano, Enrique Dussell o el Ché y, desde luego, que está en el trasfondo del ideal bolivariano.

Gabriela Bayona-Trejo

gabriela.bayona@uacm.edu.mx

Mexicana. Licenciada en Letras Inglesas, Universidad Nacional Autónoma de México (UNAM). Profesora-investigadora de Tiempo Completo, Universidad Autónoma de la Ciudad de México (UACM). Temas de investigación: alfabetización académica, traducción y promoción de la lectura. ORCID: https://orcid.org/0000-0003-3552-4544.

Recepción: 15/10/21. Aprobación: 10/12/21.

\footnotetext{
${ }^{1}$ Reseña del libro coordinado por Daniela Rawicz (2020), Leer a Simón Rodríguez. Proyecto para América, México, Universidad Autónoma de la Ciudad de México, 224 pp., ISBN 978-607-8692-22.
} 
Los primeros dos ensayos, compuestos por María del Rayo Ramírez Fierro y Mariana Brito Olvera respectivamente, presentan un esbozo de Simón Rodríguez el ser humano. Lo llamo esbozo, porque parte de la obra del filósofo se perdió en un incendio $\mathrm{y}$, aunque sí se conservan varias publicaciones y hay datos y testimonios diversos, no tenemos todos los pormenores de cómo era, ni de su vida, por lo que se presta a conjeturas e invenciones, por ejemplo, sobre su físico. En el libro se presentan distintas versiones de retratos de Simón Rodríguez, que claramente difieren en su fisonomía. Nos comenta María del Rayo Ramírez que el más fidedigno es donde se presenta desaliñado y no estilizado, ni blanqueado, pues: "Este retrato lo aleja de las barberías francesas, los fracs y los corbatines de moño, propios de la autoimagen de los habitantes de la ciudad letrada y nos trae a un Simón Rodríguez, al «zambo don Simón», más acorde con su vida humilde de pensador del margen, lugar para su pensamiento crítico radical; ese pensamiento filosófico-político que propuso que en América era posible vivir sin reyes y sin congresos en la medida en que todos se asumieran como sujetos de la acción política" (Rawicz, 2020: 36). Si quieren conocer más sobre su excentricidad y su personalidad, no dejen de leer ambos ensayos.

Simón Rodríguez era un rebelde en muchos sentidos y su escritura muestra uno de ellos, como podemos ver en las imágenes de sus obras, donde la tipografía, la ortografía, el formato y el estilo de su expresión escrita presentan rasgos únicos, los cuales son estudiados a profundidad por Grecia Monroy Sánchez, Luis Felipe Cabañas Albarrán, Jorge González Ramírez y Daniela Rawicz en sus respectivos ensayos dentro del libro, donde desmontan la obra desde su empresa como proyecto editorial, su posibilidad hermenéutica, su paralelo con la notación musical en una partitura y los recursos irónicos que emplea. El contenido de la obra de Simón Rodríguez no puede desvincularse del formato en que gráficamente lo expresa, lo que vuelve su lectura en ediciones facsimilares una necesidad imperante (de ahí que el grupo de investigación también se haya preocupado por presentar las citas de esta manera, como se aprecia en las citas/imágenes que aparecen en el texto).

La propuesta filosófica de Simón Rodríguez también es estudiada en el libro; por ejemplo, Aarón Manuel Preciado Ramírez sitúa al autor con respecto a su manera de entender la razón y la naturaleza humana frente a las ideas de la ilustración, dado que Rodríguez tiene un particular modo de considerar el concepto de razón, pues le añade un horizonte ético, sensible y materialista.

La propuesta pedagógica, que también es política, de Simón Rodríguez es analizada en los ensayos centrales del libro, y quiero aclarar que digo centrales en el sentido de su disposición en la obra, aunque también de mi interés personal como profesora. Sus autores son María del Rayo Ramírez Fierro, quien reconstruye la didáctica rodriguista, Richards Alberto Monroy Acosta y Edgar Gabriel García Rodríguez, quienes trazan un paralelismo con Paulo Freire. Simón Rodríguez sabía que la transformación social pasa por la educación y propuso un gran proyecto en este sentido que, por las circunstancias y el contexto, no pudo consolidar. He aquí algunos de los principios educativos rodriguistas: 
Ramos de Enseñanza

METODO i MODO de Enseñar

Conducta del Maestro con los discípulos

En los 14 puntos, que se indican en la pájina 5. para la Instruccion Social de los Niños, tiene el Maestro un repertorio de Lecciones, para dar una cada dia, insistiendo siempre sobre la Confraternidad.

METODO..... (por el camino)
es decir... por el UNICO, o por el MEJOR que haya, es una SUCESION de ACCIONES, puestas en el orden que pide la

OBRA MATERIAL O MENTAL. ejecucion de una

Enseñen los Niños a ser PREGUNTONES!

paraque, pidiendo el POR QUE, de lo que se les manda hacer,

se acostumbren a obedecer.... a la RAZON!

nó a la AUTORIDAD, como los LIMITADOS

ni a la COSTUMBRE, como los ESTUPIDOS.

¡Cuantos hombres de JUICIO, no tienen qué pasar por uno o por otro, sin poder remediarlo!

\section{MAESTRO}

es el dueño de los Principios

de una CIENCIA, o de un ARTE, sea Liberal, sea Mecánico, i que, transmitiendo sus Conocimientos,

sabe hacerse ENTENDER i COMPRENDER, con GUSTO.

i es EL MAESTRO! por excelencia,

si aclara los Conceptos i ayuda a estudiar,

si enseña a aprender, facilitando el trabajo,

i si tiene el DON!

de INSPIRAR a unos, i EXCITAR en ótros, el DESEO de SABER.

El objeto de la INSTRUCCION es la SOCIABILIDAD

i el ........ de la Sociabilidad es hacer menos penosa la vida

$$
\text { Consejos de amigo..., 1851, p. } 61
$$


Por eso, leer a Rodríguez invita e incita a romper con los moldes educativos tradicionales.

Finalmente, quiero cerrar esta reseña comentando el último capítulo del libro, donde la experiencia de crear un "periódico rodriguista" es narrada por Alfredo Fabián Díaz Rendón, Gabriela Verónica Trinidad Velázquez, Itzel Vanessa García de Jesús, Omar Velasco Ortiz, Sandra Nayeli González Trejo y Sandra Nicté Solís Sánchez, estudiantes del curso "Problemas de Filosofía en México y Latinoamérica", con la profesora María del Rayo Ramírez. Este proyecto es el vivo ejemplo de llevar a la práctica los ideales de Simón Rodríguez en el sentido de resquebrajar la solemnidad academicista, cuestionar y replantear la educación de una manera lúdica, social y mediante el aprendizaje cooperativo. Sin embargo, mi única queja del libro aparece en esta sección: las imágenes del periódico son muy pequeñas y difíciles de leer, ojalá en próximas ediciones las puedan ampliar.

Este último capítulo también es ejemplar de otra característica que comparte con la confección de todo el libro y que me parece maravillosa: sus autores y autoras dentro del grupo de investigación " $\mathrm{O}$ inventamos o erramos" (nombre que surge de una cita de Simón Rodríguez, por cierto, y que hace referencia a que en América no debemos simplemente copiar las ideas y propuestas externas) son docentes y estudiantes de la UACM y la UNAM que confluyen y escriben ponencias y ensayos en comunidad, organizan las jornadas rodriguistas cada semestre y comparten las responsabilidades en conjunto. En este espíritu de educación transformadora y horizontal celebro este libro, que espero pronto inspire a muchas personas a leer a Simón Rodríguez y a poner en práctica sus ideas en las aulas.

Cómo citar este artículo:

Bayona-Trejo, Gabriela (2022), "Reseña del libro coordinado por Daniela Rawicz, Leer a Simón Rodríguez. Proyecto para América”, Revista Iberoamericana de Educación Superior (RIES), vol.XIII, núm. 36, pp. 217-220, DOI: https://doi.org/10.22201/iisue.20072872e.2022.36.1192 [Consulta: fecha de última consulta]. 